\title{
Big Data Application Research in the Private Enterprises Improves Efficiency
}

\author{
Xiaoyun Fan ${ }^{1, ~ a}$, Jianfeng $L u^{2, b}$ \\ ${ }^{1}$ Computer Department, Liaoning Petro-chemical Vocational \& Technology College, Jinzhou, 121001, \\ China \\ ${ }^{2}$ College of Finance and Trade, Bohai University, Jinzhou, 121013, China \\ a30270688@qq.com, blujianfeng9999@126.com
}

Keywords: Big data, Private enterprises, Efficiency

\begin{abstract}
In the era of big data, there are no obvious boundaries between consumers. Big data is the core of the private enterprise resources, has important effects on the business model of private enterprises, private enterprises, if not by big data more close to the consumers, a deep understanding of consumer demand, efficient analysis data and make reasonable anticipation, its decline is inevitable. Data is an asset, how to activate data assets, make it a private enterprise decision service, is the core issue of big data. Big data mainly comes from the internal operation information of private enterprises, interactive information in the Internet world. The amount of information is far beyond the capacity of existing IT architectures and infrastructure. The benefits of the big data era will set off a new wave of information investment and construction boom. In the era of big data, private enterprises face the challenges of culture, strategy, organization, process, information technology, public relations and personnel training. It also ushered in a major transformation opportunity.
\end{abstract}

\section{The Definition of Big Data}

Big data in the official organization is defined as: big data is a kind of new processing pattern is needed to have strong decision-making, insight found resistance and process optimization, the huge amounts of high rate rights over with a variety of information resources. Big data does not exist because of the large data, but it is in the proper handling of these meaningful data. If we compare the big data to a specific industry, the key to profitability is to improve the "processing and packaging capacity" of the data, and the "value-added" of data can be achieved through "processing" process to achieve the profit purpose.

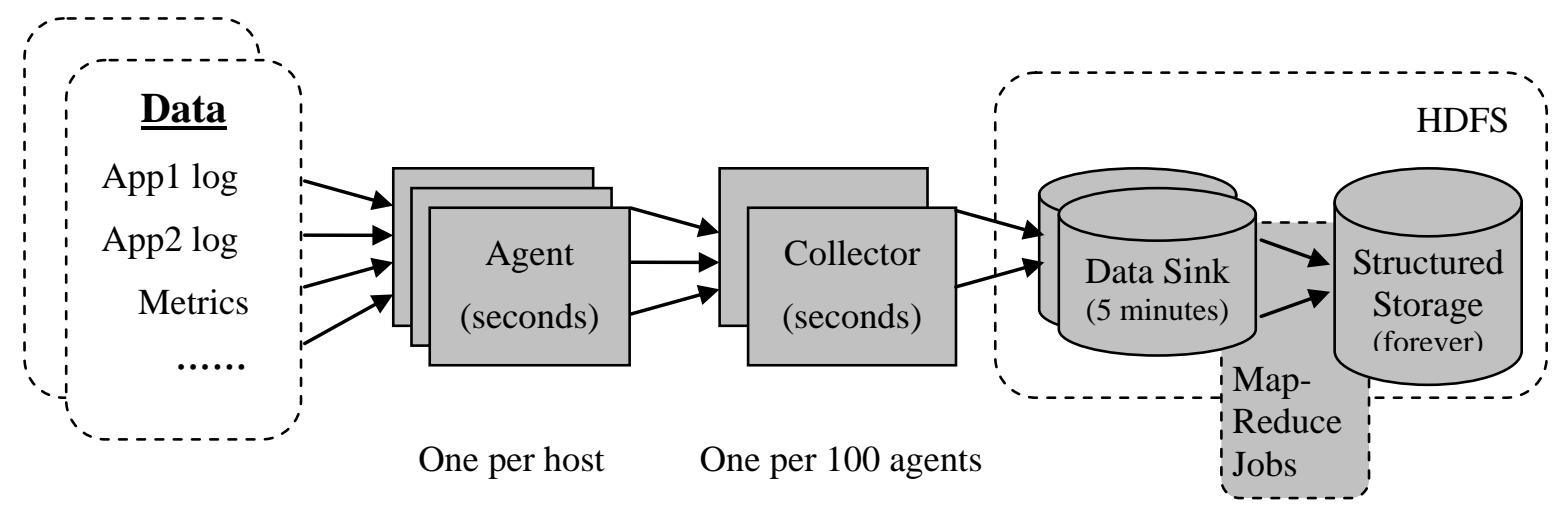

Fig 1 Map Reduce

To some extent, big data and cloud computing are complementary to each other, big data technology can't use a single server computer to deal with data, rather than through the distributed architecture, cluster and other ways to achieve the purpose. It is characterized by large amounts of data for distributed data mining, but at the same time it must rely on the cloud computing distributed processing, the cluster server, distributed database, cloud storage, virtualization 
technology, etc. With the development of The Times, we enter the cloud age, so the big data is also getting a lot of attention. Big data is generally used to describe a company or industry to create a large number of unstructured data and semi-structured data, the data in the download to the relational database is applied to the analysis of the process of spend a lot of energy and money.

Big data technology analysis is often associated with cloud computing, because large datasets analyze a framework similar to Map reduce that assigns different jobs to dozens, hundreds, or even thousands of computers. Therefore, big data and cloud computing must be combined to fully display its characteristics. Large data must not be processed with a single computer, and a distributed computing architecture or cluster server must be used. It is of huge amounts of data mining, but it must be based on cloud computing, distributed processing, distributed databases, cloud storage and virtualization technology to realize data segmentation after each node to run concurrently processing, in order to effectively deal with a lot of tolerance data after a period of time. In the era of big development data, it is possible to adapt to the trend of The Times. All traditional product companies can become the subsidiary products of new-type user platform level companies. The business model is the core of cloud computing and its essence is data processing technology.

\section{The Development of Big Data in China}

The application of big data can improve the efficiency of related industries. Then, there are the decision-making level, marketing ability, supply chain management and market opportunities of private enterprises. Ten years ago, we talked about data application, data mining, data value, long time learning and deep communication with customers. Now $50 \%$ of private business executives are very concerned about the application of big data. Private enterprises use big data to promote self-improvement, and operate their own business by using big data as the core business model.

Big data is essentially a method of thinking and the thinking and method is based on a large amount of data interconnection and quantitative, through data collection, analysis, and mining, the application in order to achieve highly intelligent and wisdom of the whole world. Big data already exists abroad, and there are good products and services companies. Foreign big data industry chain is relatively complete, there are big data technology companies, also have big data application companies. However, Google itself is typical of large data private enterprises with strong technology, which applies big data to advertising industry, driverless industry and so on. Compared with foreign countries, our domestic big data is still in the initial stage, but the development momentum is fierce. Big data has become a national strategy, written in the 13th five-year plan. Whether science and technology developed area, or a less developed region, is actively promote the development of cloud computing, big data, big data to upsurge, make domestic economic and social development into the new era. Big data changes industry marketing and management patterns, spawning new business models. Big data is already a hot word, private enterprise use big data undoubtedly can promote self improvement.

\section{To Improve the Efficiency of Private Enterprises in Big Data Analysis}

The high quality of the data analysis is of great help to the development of private enterprises in the future, for private enterprises, the accuracy of the data determines the future decision right or not, and big data analysis is that must be pay attention to in the process of development of private enterprises, not flexible data analysis system, private enterprises will not be able to understand the status of the running, in time for the existing problems will not be able to see in time, so once the problems would be irreparable.

Modern private enterprises are slow to analyze big data, especially some small and medium-sized private enterprises. Private enterprises can improve the efficiency of big data analysis from several aspects: 


\subsection{Simplify the data}

As we all know, China's private enterprises data is very complex, especially the Oracle database, many data are across data sources, to be obtained the complex technology will also bring certain obstacles to private enterprise running. To simplify this, it is not to omit some numerical values, but to realize the simplification of data through better technical means, which can improve the ability of large data analysis of private enterprises.

\subsection{Demand and problem solving should be done in the shortest possible time}

Many private enterprises have found such problems, when the private enterprises have problems, they will not be solved timely. Especially when a problem is presented to the technology, it usually takes a week or longer to solve the technology, which brings great resistance to the development of private enterprises. In the process of private enterprise development, time is of great importance, and sometimes preemptive step can compete with competitors to seize business opportunities, thus occupying the competitive advantage.

\subsection{Address the burden of technical personnel}

Technical personnel is not every moment waiting to solve the problem of data, they have their own work to do, as for the problems, such as data analysis, they need to solve problems in hand before, this will delay the use of private enterprises. And even doing it first will affect other work. If we can solve the problem of technical staff in time, we believe that private enterprises will make great progress in big data analysis.

The best way to do this is to use the BI system. BI business intelligence platform can solve the problems encountered by private enterprises in a timely manner and provide effective solutions to private enterprises to help private enterprises adjust their policies better. After using BI system software, private enterprises can not only obtain data value easily, but also can further data mining, so that private enterprises can have better reference basis in decision making.

\subsection{Big data is used internally}

Compared with big data marketing, big data has more in-depth application in internal operation, and higher requirements for information level and data acquisition and analysis ability of private enterprises. In essence, the external mass consumer data of private enterprises is connected with the mass operation data of private enterprises, which gives new insight into the analysis and improves operation efficiency.

\subsection{Big data is used for decision making}

In the era of big data, private enterprises face many new data sources and huge amounts of data, can be based on the data of insight, to make decisions, and then turn it into a privately operated enterprise the source of competitive advantage? Big data is the most difficult to use when compared to big data marketing and big data, because it requires a thinking habit that relies on data.

A handful of private companies have tried. Domestic some financial institutions such as the launch a financial product, will be widely analyzed the application and effect of the financial products, target customer group of data, transaction data and pricing data, etc., and then decide whether to launch a financial products.

However, China academy of private entrepreneurs in the survey found that at present China's private enterprises, large data decision application is very few, many private enterprises leaders to make decisions, is still used to relying on historical experience and intuition.

Big data products - the new source of profits growing of private enterprises, large data except for operation, also can combine with products of private enterprises, become private enterprise product competitiveness at the core of the support behind or become products directly. Private enterprises that provide large data products are divided into two categories, which directly provide large data products private enterprises, as well as private enterprises that provide big data as the core support of products and services. The former is mainly for the large data to provide data service in the 
industry chain of participants, including data owner, storage, private enterprises, private enterprises and analysis of private enterprises in mining, etc., the latter is mainly in the big data core support for the products of private enterprises, private enterprises, most of them are Internet its inherent in products and services with large data gene, these private enterprises include search engines, online antivirus, Internet advertising trading platform as well as many is built on the mobile Internet, to provide users with the life and the information service of the APP, etc.

\section{Big Data Changes the Marketing Mode of Private Enterprises}

The essence of big data marketing is to influence the psychological path of target consumers before shopping, which is mainly used in three aspects: big data channel optimization; Accurate marketing information push; Connect online and offline marketing. Before consumer shopping, through various means, directly involved in its information collection and decision-making process. This kind of intervention is based on the analysis of online and offline mass user data. Big data marketing has a great advantage in both initiative and precision, compared with the traditional bombardment or waiting marketing. It is the main application area of big data. Data marketing doesn't just use big data to identify target customers, but it can also do it:

\subsection{Implementation channel optimization}

According to user's Internet traces to optimize channel marketing effect and track customer's behavior is based on the Internet to find out which marketing channel has the most customer source, which source the most customer actual purchases, whether or not the target customers, and so on, so as to adjust the marketing resources in various channels. Dongfeng Nissan, for example, USES tracking of customer sources to improve marketing resources on various web portals such as portals, search and micro blogging.

\subsection{Accurate marketing information push}

Precision based on the huge consumer behavior analysis, consumer web browsing, search behavior was left network, offline purchase and view such behavior can be store POS machine and video monitoring records, plus they leave the identity of the information in the purchase and registration process, in front of merchants, is gradually showing a sea of consumer information.

\subsection{Through online and offline marketing}

Some private enterprises have been able to reach the online and offline marketing by linking the behavior trace data of Internet Shanghai and offline purchasing data. Dongfeng Nissan, for example, the coordination of online and offline marketing methods as follows: the portal to bring order clues, and through these clues, telephone pays a return visit, service personnel to promote customer trading below the line. Were recorded in the process, Dongfeng Nissan consumers access, browse, click, registration, phone pays a return visit and buy each link of the data, implements a across online, with large data analysis to support, constantly optimize the marketing effect of closed loop marketing channel. And China's double technology, to measure the effect of an area's offline promotion activity, is to look at the Internet, from this area to promote the content of the search volume.

\section{Conclusion}

Private enterprises can change and optimize operation decision-making, marketing and management through big data. Based on more and more extensive and faster data analysis and mining, the development of private enterprises can be improved, and the new business model can be generated through data. Private enterprises can run their own business by using big data as the core business model. The application of big data can improve the efficiency of industry. Then, there are the decision-making level, marketing ability, supply chain management and market opportunities of private enterprises. It is essential to apply big data to industrial development. 
Some private enterprises by collecting vast amounts of consumer information, and then using big data modeling technology, according to the attributes and consumer interest, buying behavior, such as dimension, mining target consumers, then classify, and then based on these, to marketing information push the individual consumers. Such as mummy maternity brand October through to the Weibo fans comment on large data analysis, find out comments have fans of "love" related keywords, and then tagged, and push on the marketing information. Li xi, deputy general manager of Jingdong mall, said: "using big data to find out different groups of customers and then marketing them accordingly is what Jingdong is doing now."

Some private enterprises, by encouraging offline customers to use WeChat and wifi, such as the equipment of consumer behavior and preferences, to get through online and offline data stream, Yintai department plans laid wifi, encourage customers to use inside the mall, then according to the wifi account, find out the customers, through cooperation with other major data mining company, again by means of large data, find the customer in the history of the Internet, to understand the customer requirement types.

\section{Acknowledgement}

This work is supported by social science fund project of Liaoning province: Study on investment expansion and efficiency loss of small and medium-sized private enterprises in Liaoning province from the perspective of government association (L17DGL001).

\section{References}

[1] Chen, C. J. P., Z. Li X. Su, and Z. Sun. Rent-Seeking Incentives, Corporate Political Connections, and the Control Structure of Private Firms .Journal of Corporate Finance,2011,17(2): 229-243.

[2] Wan W. P., Hoskisson R. E., Short J. C. et al. Resource-Based Theory and Corporate Diversification [J]. Journal of management. 2011, 37(5): 1335-1368.

[3] Faccio M. Differences between Politically Connected and Nonconnected Firms: A Crow Country Analysis [J]. Financial Management, 2014, 39(3):905-928.

[4] Lifeng Gu. Product market competition, R\&D investment, and stock returns [J]. Journal of Financial Economics. 2015(2):6-12.

[5] Jing Han, Jian Han, Daniel J. Brass. J. Organiz. Behav. .Human capital diversity in the creation of social capital for team creativity [J]. 2014 (1):25-31. 